\title{
APOCALIPSIS, EVENTO Y UTOPÍA BADIOU Y ŽIŽEK A TRAVÉS DE LA FICCIÓN
}

Apocalypse, Event and Utopia

Badiou and Žižek through Fiction

\section{Jorge Fernández Gonzalo \\ (UCM, España)}

\begin{abstract}
Resumen
Nuestro estudio trata de analizar el concepto de Apocalipsis y de acontecimiento en la filosofía contemporánea y a través de la ficción audiovisual. Para ello, utilizamos las propuestas de Alain Badiou, Slavoj Žižek y el psicoanálisis, junto con referencias cinematográficas como Los pasajeros del tiempo (Escape al futuro) o Peggy Sue se casó, y series de televisión como Flashforward o Perdidos.
\end{abstract}

Palabras Clave: Apocalipsis | Deseo | Acontecimiento | Badiou | Žižek.

\begin{abstract}
Our study attempts to analyze the concept of Apocalypse and event in contemporary philosophy and through audiovisual fiction. To do this, we use the proposals of Alain Badiou, Slavoj Žižek and psychoanalysis, with film references such as Time after Time or Peggy Sue Got Married, and TV series such as Flashforward and Lost.
\end{abstract}

Keywords: Apocalypse | Desire | Event | Badiou | Žižek.

En este artículo analizamos las características del acontecimiento tal y como lo definen pensadores de la talla de Alain Badiou o Slavoj Žižek, en relación con un horizonte utópico/apocalíptico que se dibuja en nuestro marco político ficcional. La brecha que separa nuestro presente del futuro es, necesariamente, parte de nuestro presente. O dicho de otro modo: el futuro es ahora, pero se manifiesta siempre a través de formas de ficción, en las fantasías literarias o fílmicas que utilizan la utopía y el apocalipsis como principales figuras retóricas con que nombrar el mañana.

De este modo, recurrimos a diferentes creaciones que permiten representar los tiempos advenideros en un juego calculado entre la pulsión apocalíptica y las esperanzas utópicas. La tesis que defendemos aquí es que, a cierto nivel, ambas figuras coinciden: ¿̇y si los imaginarios utópico/apocalípticos - pensemos en obras de ficción con los Juegos del hambre, Divergente, etc.- tuvieran como finalidad justamente ocultar que el acontecimiento es, aquí y ahora, posible? Nuestra propuesta, por tanto, pasa por incidir en la dimensión del evento revolucionario, el verdadero acontecimiento liberador, como un hecho sin programa, un acontecimiento traumático que se oculta tras las huellas que 
despliega la ficción audiovisual contemporánea.

\section{El capitalismo es la Utopía}

Cabe iniciar nuestro análisis del fenómeno utópico/apocalíptico con unas reflexiones en torno a la película Los pasajeros del tiempo (Time After Time, 1979), una producción de viajes en el tiempo que reelabora la clásica novela de $\mathrm{H}$. G. Wells The Time Machine (1895). En la cinta, es el propio Wells quien se transporta hasta la fecha actual (en realidad, el año de estreno de la película) para perseguir a Jack el destripador, que ha escapado desde la época victoriana tras robar el artefacto que el propio Wells había inventado. Por fortuna, un mecanismo permitía que la máquina retornase al punto de partida, por lo que Wells ha logrado utilizarla para buscar a su contemporáneo y poner fin a sus actos delictivos transtemporales. El famoso escritor fantasea en los primeros minutos de metraje con unos años setenta que consolidarían el ideal socialista, una época en donde las injusticias han sido paliadas y la dignidad universal del ser humano no es una promesa inalcanzable, sino un hecho consumado. Cuando llega a 1979 (a Utopía, según sus palabras) acaba obviamente decepcionado al descubrir que nada es como esperaba: la degradación moral de una sociedad distraída que se deja llevar por la inercia de una era hiperconsumista incipiente no se parece en nada a la imagen que Wells había vislumbrado en sus ensoñaciones.

La primera lectura que podemos trazar a partir de este episodio consistiría en concebir nuestro sueño utópico como un artefacto incompleto, un proyecto enviciado por los primeros coletazos de una globalización en ciernes. La lectura más arriesgada, no obstante, sería la siguiente: ¿y si este Wells de ficción llegó a escribir la novela que todos conocemos tras regresar de nuestro tiempo al suyo, utilizando como materiales narrativos las injusticias sociales de las sociedades de finales de los setenta? Desde esta perspectiva, los despiadados morlocks constituirían la representación monstruosa de las embrutecidas clases bajas de un subproletariado tercermundista que apenas sale de la oscuridad de sus fábricas para ver la luz del día, mientras que los ensimismados eloi darían cuerpo a la distraída clase media-alta que recibe gozosamente los parabienes del capitalismo hiperconsumista sin preguntarse de dónde ha salido todo aquello. La película de 1979, por tanto, habría reescrito el libro de Wells hasta convertirlo en una crónica del último tercio del siglo XX.

No obstante, hay una lectura más que podemos elaborar a partir de la cinta, en una suerte de tercer término dialéctico: ¿y si en realidad este Wells de ficción estuviera equivocado? ¿Y si el capitalismo constituyera la verdadera utopía? Frente a las políticas estamentales del antiguo régimen, el capitalismo cumplía el sueño de convertirnos en ciudadanos emprendedores llamados a ascender socialmente, alcanzar dinero o fama a pesar de unos orígenes humildes, etc. Del mismo modo, cabe pensar que la abstracción económica, el hecho de que todo pase por su traducción monetaria (la fuerza de trabajo, las emociones, los conflictos violentos incluso), ofrece la ventaja de eliminar las discrepancias antagónicas: en lugar de perpetuar luchas transgeneracionales entre familias, una multa económica o una compensación libera a unos y otros, ofendidos y ofensores, de tener que asumir la culpa o la venganza. De este modo, en lugar de discutir con un desconocido, pago una cantidad que permita resolver el agravio, o contrato una agencia, un abogado o cualquier otro recurso externo que me permita trocar el exceso insoportable de determinadas transacciones humanas por abstractos mecanismos de intercambio simbólico regulado. La pesada losa de soportar al otro (a través del amor, de la cortesía, etc.) puede ser saldada con una retribución económica consensuada. Lejos de situarnos en la órbita de Eva Illouz (2007) o Eloy Fernández Porta (2008, 2011), cuyos concienzudos 
análisis sobre el entrecruzamiento entre flujos de capital y flujos de emociones perfilan una interesante imagen de las categorías que conforman el paquete básico de los modos capitalistas actuales, proponemos la versión estrictamente opuesta, y es la posibilidad de emplear las convenciones simbólicas que participan en todo intercambio económico como límites o barreras para evitar el paso de flujos de afectividad.

La tesis que planteamos aquí es tan incómoda como necesaria, si bien no está completamente huérfana de apoyos teóricos. Pensemos en las bases sentadas por el psicoanálisis, principalmente el psicoanálisis lacaniano, y en sus propuestas sobre la economía libidinal. El mayor problema al que hemos de enfrentarnos es que, a un nivel profundo, no deseamos aquello que abiertamente manifestamos querer (como lograr determinados cambios en nuestra vida, obtener un trabajo mejor, buscar pareja cuando estamos cómodamente solteros o no tenerla cuando nos sentimos oprimidos con ella, etc.), sino que las divagaciones del deseo se desenvuelven a través de aquello mismo que impide su realización: aunque quiero un trabajo mejor que éste, me aferro al que tengo para evitar así perder la estabilidad lograda, o con el fin de complacerme ante la idea de que sería más feliz si hubiera tenido suerte en la vida, etc. En palabras de Žižek (2001: 326): «nuestro deseo no es nunca en realidad el deseo explícito que podemos formular: nunca deseamos verdaderamente lo que deseamos o queremos. Por esta razón, no hay nada más horrible (precisamente, más deseable) que una Cosa que realice inexorablemente nuestro verdadero deseo». El objeto de deseo está constituido, de este modo, por su propio retardo, por aquello que lo obstaculariza. Lo que nos separa del objeto no es otra cosa que el deseo mismo y la distorsión que éste introduce en una relación libidinal. Hemos de hablar aquí del goce, el deseo por el obstáculo que impide mi propia obtención de placer, lo que nos permite protegernos de nuestras inclinaciones libidinales. $\mathrm{O}$ como reza la conocida expresión atribuida a Oscar Wilde, cuidado con lo que deseas, pues tus deseos podrían hacerse realidad.

Esta misma noción se encuentra ya en Freud. Además del famoso estigma de Midas, quien era capaz de convertir en oro todo aquello que tocaba, podemos recurrir, con el padre del psicoanálisis, a la historia del anillo de Polícrates para cifrar los enigmas de la economía del deseo. El tirano de Samos era conocido por un episodio fantástico del que se hace eco el mismo Heródoto: Polícrates había decidido ofrecer un sacrificio a los dioses y, para mostrar su humildad ante ellos, decidió tirar al mar su posesión más preciada, un anillo de esmeraldas de gran valor. Pero desde el momento en que se desprendió de él no pudo evitar sentirse sumamente arrepentido. Cuál habría de ser su sorpresa cuando, pocos días más tarde, un pescador le obsequió con una pieza de gran tamaño que albergaba en su interior el preciado anillo. La leyenda cuenta que, desde entonces, todo aquello que el tirano deseaba se hacía realidad. Por ello, era observado con recelo por otros gobernantes; «los demasiado dichosos - apunta Freud- tienen que temer la envidia de los dioses» (1979: 239).

Tomemos como ejemplo otra película de viajes en el tiempo, la cinta Peggy Sue se casó (1986). En ella, tiene lugar una clara escenificación de esta dialéctica del deseo que permite cumplirlo a condición de derivarlo hacia el goce por su propia imposibilidad. Peggy Sue, una mujer de mediana edad que acaba de divorciarse de su marido (el actor Nicholas Cage), acude a una reunión de viejos alumnos de instituto y, de repente, es mágicamente transportada a su época de estudiante. En una escena concreta, vuelve a flirtear con su marido cuando aún eran una inexperta pareja de novios adolescentes. Ambos se besan en el coche, pero ahora es ella quien toma la iniciativa y le propone llevar a cabo el acto sexual, a lo que él se niega completamente asustado. La dialéctica del deseo es su formulación lacaniana está aquí perfectamente representada: mientras que él aparentaba en todo momento querer acostarse con su novia, en verdad su más íntimo deseo consistía en esperar una renuncia por parte de ella (que apartara su mano del 
abotonado de la blusa, que le reprendiese por meter demasiado la lengua durante un beso, etc.) para que así su autoritaria masculinidad quedase indemne sin tener que pasar por la engorrosa situación de poner a prueba sus escasas habilidades sexuales. El deseo de él se estructura a través de la fantasía de que «casi» pudo cumplir su falso anhelo, mientras que ella, con la mentalidad de una mujer adulta sexualmente realizada, ha conseguido dar rienda suelta a sus apetitos carnales desestimando las falsas coqueterías adolescentes.

Esto mismo es lo que sucede en relación a las demandas políticas y al cortocircuito que produce el goce comunitario. En el contexto español, es habitual que la derecha entone el recurrido lema de «con Franco se vivía mejor». La dictadura benefició a una clase que hoy pretende mantener o incluso incrementar sus privilegios y que mira con añoranza los años en que sus intrigas políticas o económicas estaban amparadas por la tutela institucional. La izquierda, sin embargo, puede decir lo mismo, sólo que en la fórmula invertida que propuso muy acertadamente el novelista Manuel Vázquez Montalbán: «contra Franco se vivía mejor». La contracultura no desea, en muchos casos y a un nivel profundo de su economía libidinal, acabar con el capitalismo, las dictaduras o la globalización, sino que prefiere vivirlo como goce, a modo de obstáculo inherente a su propio deseo revolucionario. El panorama que encuentra el defensor de la democracia es que se han producido cambios sustanciales tras la caída del régimen dictatorial de Franco (el neoliberalismo económico, el ascenso de las megacorporaciones y su colonialismo interior, el relativo éxito de los programas sindicales y su posterior simbiosis parasitaria con las estructuras de poder a las que pretendían enfrentarse, etc.), lo que a la larga ha provocado consecuencias mucho más catastróficas de las esperadas. Pensemos, en esta misma línea, en el ejemplo que propone Žižek cuando habla de los intelectuales de izquierda y de su cómoda posición, por la cual no quieren que nada cambie realmente, es decir, necesitan gozar del hecho de que sus demandas no sean plenamente satisfechas, pues en definitiva no podrían soportar un escenario político en el que no pudieran entonar sus inocuas reivindicaciones:

\begin{abstract}
cuando los académicos "radicales" exigen derechos plenos para los inmigrantes y la apertura de las fronteras a todos ellos, ¿son conscientes de que la instrumentación directa de esa demanda inundaría, por razones obvias, los países occidentales desarrollados de millones de recién llegados, lo cual provocaría una violenta pelea racista en la clase trabajadora que luego terminaría poniendo en peligro la privilegiada posición de los mismos académicos? En este sentido, pueden conservar hipócritamente su limpia conciencia radical mientras continúan disfrutando de su posición privilegiada (Žižek, 2005: 63-64).
\end{abstract}

En conclusión, el enfoque que nos permitiría entender nuestro contexto global consiste en ver los actuales estados democrático-capitalista-neoliberales como el cumplimiento obsceno de nuestros deseos. El problema del capitalismo podría ser justamente ése: que ha conseguido darnos aquello mismo que anhelábamos (obviando, por supuesto, los períodos de crisis, o el excedente inmigrante/lumpemproletario que ha quedado fuera del reparto del pastel). El lema que definiría nuestro entorno político/libidinal se resumiría en la fórmula cuidado con lo que deseas, porque tus deseos podrían cumplirse a través del capitalismo. Pensemos en la novela de Ursula K. Le Guin La rueda celeste, en donde nos encontramos con el mismo motivo que describía Freud. En este caso, el protagonista, George Orr, acude también a la consulta de un psiquiatra y le confiesa que su adicción a las drogas sirve para mitigar sus sueños, ya que éstos poseen un extraño poder: el de hacerse realidad retroactivamente. Sus fantasías no sólo se cumplen al despertarse, sino que el resto de personas actúan como si todos los cambios hubieran sido así desde siempre. En una sesión, el doctor comprueba la veracidad de los sucesos que le relata su paciente, por lo que decide guiar, mediante hipnosis, sus próximas ensoñaciones para crear un mundo 
mejor. Por supuesto, esto deparará trágicas consecuencias: cuando el psiquiatra le induce a que halle en sus sueños una salida a los problemas de superpoblación, sus fantasías recrean una plaga global que ha diezmado a la mayor parte del planeta. La realización de la utopía, necesariamente, arrastra consigo un nuevo escenario antiutópico, como si la culpa del Apocalipsis hubiera de ubicarse, necesariamente, en la utopía. Si bien también podemos hacer frente a la tesis contraria y reivindicar que la verdadera utopía es, claramente, el Apocalipsis, es decir, el momento de ruptura/reinicio que nos permite reconfigurar el mapa de relaciones existentes.

\section{Romper con la utopía: El evento}

A propósito de nuestras reflexiones, cabe traer a colación un motivo teórico que nos permitiría «romper con la utopía», es decir, salir del circuito de recompensas libidinales constantes que nos ofrece el capitalismo a través de un acontecimiento auténtico. El concepto de Evento nos remite a las teorizaciones políticas que propone el filósofo Alain Badiou y que recientemente ha secundado Slavoj Žižek. Lo político, recuerda Alain Badiou (2009), no se define por la pluralidad de opiniones que convergen hacia un marco de optatividad democrática, sino por la garantía de ruptura con lo existente. Y ese acto de ruptura tiene un nombre específico dentro de la terminología badiouana: el evento. La política se extiende sobre aquello que la pone en estasis, la paraliza y la destruye, y únicamente puede ser pensada a través de esa quiebra constitutiva. En las primeras páginas de uno de sus últimos textos, Žižek indica que el acontecimiento o evento «puede hacer referencia a un desastre natural devastador o al escándalo más reciente provocado por una celebridad, al triunfo del pueblo a un cambio político despiadado, a la intensa experiencia de una obra de arte o a una decisión íntima» (2014: 15). Su naturaleza podría definirse como «milagrosa», no en el sentido religioso de intervención divina, pero sí como momento de ruptura, corte con respecto a un estado anterior que tiene lugar por cuestiones parcialmente inexplicables.

El acontecimiento, el evento político, se presenta como un fenómeno retrocausal, supone una ruptura que necesariamente organiza y recompone el relato de su propio surgimiento ex nihilo. El evento crea la verdad del evento, así como las coordenadas que lo rodean; está condenado a ocurrir después, a suceder únicamente en el futuro, mediante su inscripción en una red simbólica (ya que, por su propia dimensión catastrófica y en cuanto que acto fallido abierto a lo indeterminado, está «lleno de futuro»), pero también tiene lugar antes, a través de la brecha que ya existía en esta red y que se prepara para acogerle. Contra la concepción de Hegel, para quien un hecho entraba en la existencia sólo cuando todas las condiciones están presentes, hay que contraponer la propuesta bergsoniana/badiouana que ve en la aparición del acontecimiento el punto de inscripción retrocausal de una red de hechos inconexos. Más que una linealidad genealógica, podemos hablar de retrocausalidad, o como hace Badiou, de resonancia: algo que ocurre aquí tiene repercusiones allá, encuentra, su eco en otro punto del espacio y del tiempo. La novedad de este acontecimiento sucede en unas condiciones determinadas de poder que adquieren su significación política plena después de que el acontecimiento haya certificado su existencia y la existencia de aquellos que, en términos políticos, carecían de ella. No en vano, Rancière calificaba la acción política como «el arte de lo imposible» y Derrida secundaba esta idea al hablar de «la venida de lo imposible» para referirse al acontecimiento. Si bien fue Justiniano el primero que supo ver la relación paradójica entre certeza e imposibilidad que subyace en el acontecimiento, en concreto a colación del «acontecimiento» que supuso el Cristianismo: Certum est, quia impossible (es cierto porque es imposible). Hay, por tanto, una imposibilidad consustancial al evento badiouano, que al mismo tiempo 
constituye su condición de posibilidad.

De este modo, un acontecimiento «no es algo que ocurre en el mundo, sino un cambio de planteamiento a través del cual percibimos el mundo y nos relacionamos con él» (Žižek, 2014: 23-24, en cursiva en el original). No hemos de confundir, por tanto, este tipo de suceso con el acontecimiento visto por la filosofía de Gilles Deleuze, quien hablaba de una gran calma que empieza a extenderse, hasta explotar; el propio exceso, su vibración sostenida, quiebra en el momento preciso (Ibíd.: 134). Muy al contrario, el acontecimiento žižekiano/badiouano remite a un punto de torsión, de quiebra, cuya esencia estriba en su propia desaparición. Se trata de un elemento indeci(di)ble, sin garantías ontológicas ni sostén alguno en la cadena causal, que excede a sus causas y cuyo espacio separa (o más concretamente, anula) la contigüidad entre causa y efecto, puesto que: «no puede ser reducido a una situación (previa) ni deducido de ella, ni es tampoco generado por ella. Surge "de la nada" (la nada que era la verdad ontológica de esa situación anterior). No hay entonces ninguna mirada cognitiva neutral que pueda discernir el acontecimiento de sus efectos: desde siempre hay una decisión implícita» (Žižek, 2001: 147). Para que una violencia auténticamente revolucionaria tenga lugar, ésta debe abrir su propio espacio ontológico (o en otros términos, debe surgir como apertura misma de dicho espacio). Se trata, pues, de un vacío imperceptible que surge cuando la situación, la cadena lineal de sucesos, ya estaba cerrada; aquello que añade el acontecimiento es una apertura, surge como una intrusión indecidible (ni dentro ni fuera del sistema en el que se incorpora) que «no curva el espacio del ser a través de su inscripción en él; por el contrario, un acontecimiento no es nada sino esta curvatura del espacio del ser» (Žižek, 2006: 202, en cursiva). ¿No estamos aquí ante una de las claves del psicoanálisis, que determina la dimensión del campo simbólico como «no-Toda» (esto es, completa a través de su incompletud, cruzado por una falta que no remite a nada exterior, etc.)? El acontecimiento es posible porque la realidad está incompleta, porque el Otro está atravesado por una falta, o expresado en los términos que maneja nuestro autor: el acontecimiento es la emergencia de lo Real, entendido como «el violento gesto generador que hace surgir el orden legal que da lugar a que ese mismo gesto se convierta retroactivamente en "ilegal", y que lo relega al estatus espectral reprimido de algo que nunca puede ser reconocido-simbolizadoexpresado plenamente» (Žižek, 2002: 121).

Pensemos aquí en el error común de los medios de prensa cuando hablan de eventos deportivos o políticos. ¿Cómo podemos calificar de «eventual», esto es, contingente, aquello que estaba previamente dispuesto? La primera lectura es que hemos domesticado el componente subversivo del acontecimiento para convertirlo en ocio programado. Pero si indagamos más descubrimos que realmente hay algo, un excedente obsceno en el propio evento, que liga su imprevisibilidad a un movimiento de repetición y concatenación programática: hay algo previo al encuentro, una situación de tensión precedente que aún estaba resonando, que no había cuajado y aún esperaba conformarse en una narrativa, adquirir un sentido pleno. En opinión de Badiou, la potencia del acontecimiento reside en su capacidad de engendrar un tiempo exclusivo, propio, una programación (retro)causal que redirige la temporalidad existente hacia su núcleo irresuelto. La revolución se mide, de este modo, como lo que siempre sucede sin tener sucesión por sí misma, el acontecimiento puro que quiebra el campo político previo, pero que al mismo tiempo determina retroactivamente sus fallas y sus posibilidades intrínsecas.

Vemos cómo esto mismo ocurre con frecuencia en la ficción actual. Existe cierto aire de época en las producciones más recientes que privilegian lo inesperado, lo eventual, un hecho fantástico a menudo fuera de toda lógica que rompe con lo cotidiano, como si el imaginario colectivo estuviera reclamando una suerte de suceso, de apertura o estallido de orden revolucionario y sólo pudiera dar rienda suelta a tales deseos a través de la ficción. Pensemos en la malograda serie Flashforward, en donde un repentino acontecimiento 
mundial trastoca la rutina diaria de los protagonistas: durante un intervalo de dos minutos y diecisiete segundos, toda la especie humana sufre un desvanecimiento y una serie de alucinaciones en las cuales se ven a sí mismos llevando a cabo las actividades que presumiblemente acometerán exactamente seis meses más tarde, el día 26 de abril de 2010. Las visiones son de lo más variado: hay quien descubre una escena cotidiana junto a una persona que aún no conoce, ricos que se ven arruinados y pobres que aparecen rodeados de lujos, familias rotas y amigos reencontrados, etc., así como unas pocas personas que no ven absolutamente nada y que presuponen que su vida acabará antes de que se cumpla el plazo de seis meses. Cuando todos despiertan, el mundo entero es un absoluto caos: la mayoría de los aviones que estaban en el aire han descendido bruscamente y se han estrellado, y miles de automóviles han sufrido algún accidente y hay problemas de todo tipo. El gran acontecimiento, por tanto, ha tenido lugar, pero a condición de prepararnos para el día después, o, en este caso, para el día de dentro de seis meses, en el que la ruptura del evento flashforward se concrete y tome forma definitiva. ¿Cómo no ver aquí las características propias del acontecimiento político badiouano?

Tenemos más productos de ficción en donde esto mismo tiene lugar. Quizá el caso paradigmático sea el de la serie Perdidos, en donde este recurso no constituye el arranque de la serie, sino una constante que se recicla durante varias temporadas: hay un accidente de avión y varios pasajeros acaban en la isla, también hay viajes en el tiempo, sueños premonitorios, descubrimientos sorprendentes sobre los secretos ancestrales de la isla y diversas líneas narrativas que unen la ciencia ficción con el género fantástico. En la más reciente The Leftover la acción se sitúa en un pueblo estadounidense tras la desaparición de 140 millones de personas, un dos por ciento de la población global, lo que da pie a diferente elucubraciones: mucha gente habla de «ascensión», en referencia a una posible actuación divina, otros hablan de alienígenas, conspiraciones del gobierno, etc. En La cúpula sucede que, repentinamente, una cúpula indestructible cubre otra pequeña localidad estadounidense, dejando incomunicados a sus habitantes y sin que sepamos, en principio, cómo ha ocurrido todo. A este tipo de series podemos sumar otras en donde el Apocalipsis coincide más abiertamente con la aparición del evento. Cabe citar aquí las películas y series de zombis, como la popular The Walking Dead, en donde el protagonista, Rick Grimmes, despierta de un coma y descubre que todo a su alrededor ha cambiado: varias personas se han convertido en «caminantes», reciclaje de los clásicos zombis de George Romero.

Encontramos más ejemplo en cine y en otros productos de ficción que demuestran cómo en nuestro imaginario colectivo aparecen los contornos de un evento revolucionario. El problema es: ¿̇acaso no es la fantasía una forma de sofocar los anhelos revolucionarios? Es decir, ¿nos contentamos con la ficción sobre el acontecimiento de ruptura, o es posible ver aquí una suerte de pedagogía de ficción que nos prepara para el evento, un marco de resonancia, como diría Badiou, que nos permita convocar todas las aspiraciones colectivas en un nuevo acontecimiento global, aún por definirse? El propio Žižek había establecido las bases de esta tesis: «¿Y el tono apocalíptico que a menudo percibimos hoy, especialmente después de que haya ocurrido alguna nueva catástrofe? La paradoja final aquí es que el catastrofismo excesivo de hoy (el mantra de que "el fin del mundo está cerca") es en sí mismo un mecanismo de defensa, un modo de ocultar los auténticos peligros, de no tomarlos en serio» (2013: 179a).

\section{Consideraciones finales}

Como ha apuntado Slavoj Žižek, la postura apocalíptica es la única que nos permite un poco de sosiego en nuestro panorama político y social («En lugar de llevarnos a un éxtasis 
autodestructivo, adoptar la postura apocalíptica apropiada es, hoy más que nunca, el único modo de mantener la calma» (2013b: 61). Todos sabemos que el Apocalipsis no llegará inmediatamente, ni ahora ni en las próximas décadas, pero siempre es un alivio volver a oír el anuncio de su llegada. Que alguien nos increpe con la proximidad inmediata del fin del mundo significa, de este modo, que todo funciona correctamente. Por otra parte, aquello que debería preocuparnos sería realmente lo contrario, que el final de los tiempos haya tenido lugar, ya que eso nos obligaría a asumir nuestras responsabilidades y a llenar el acontecimiento que se produce con su intromisión. En esta línea, Albert Camus sentenciaba acertadamente que no hemos de esperar al Juicio Final, pues, en definitiva, éste sucede todos los días. La conclusión que extraemos de este escenario es que, si el verdadero acontecimiento ha tenido lugar, aún no hemos oído bien todos sus compases, su resonancia, por lo que es preciso que nos mantengamos alerta y obremos en consecuencia. En cuestiones políticas, el campo político global ha sufrido recientemente ciertos impulsos y traspiés que no han terminado de concretarse: reivindicaciones sociales a pequeña escala y ciberrevoluciones que permiten tumbar servidores informáticos, ascenso de partidos de izquierdas en escenarios neoliberales, derrotas dentro de este marco apocalíptico y pequeñas victorias, movilizaciones solidarias globales y políticas nacionales intransigentes. Vislumbrar cuál es el verdadero acto revolucionario no parece hoy tan fácil como hace un siglo o siglo y medio; no hay un obstáculo en el camino, sino que somos incapaces de ver el camino. Los signos del Apocalipsis revolucionario están aquí, y nuestra misión es hoy más que nunca la de rastrear sus marcas, unir los despojos esparcidos y establecer un eje de confluencia de todas las ficciones, demandas y rupturas que aparecen en el horizonte.

\section{Bibliografía}

BADIOU, Alain (2009). Compendio de metapolítica. Buenos Aires: Prometeo Libros.

FERNÁNDEZ PORTA, Eloy (2008). Homo Sampler: tiempo y consumo en la Era Afterpop. Barcelona: Anagrama.

-(2011). Eros: la superproducción de los afectos. Barcelona: Anagrama.

FREUD, Sigmund (1979). Obras completas. Vol. 17. De la historia de una neurosis infantil y otras obras (1917-19). Buenos Aires: Amorrortu.

Illouz, Eva (2007). Intimidades congeladas: las emociones en el capitalismo. Buenos Aires: Katz Editores.

ŽIžEK, Slavoj (2001). El espinoso sujeto: el centro ausente de la ontología política. Buenos Aires: Paidós.

-(2002a). El frágil absoluto o ¿Por qué merece la pena luchar por el legado cristiano? Valencia: Pre-Textos.

-(2005). El títere y el enano: el núcleo perverso del cristianismo. Buenos Aires: Paidós.

-(2006). Visión de paralaje. Buenos Aires: Fondo de Cultura Económica.

-(2013a): El año que soñamos peligrosamente, Madrid: Akal.

-(2013b): El dolor de Dios: Inversiones del Apocalipsis, Madrid: Akal. Con GUNJEVIC, Boris.

-(2014). Acontecimiento. Madrid: Sexto Piso. 